\title{
Risk definition and management strategies in retinoblastoma: current perspectives
}

REVIEW

\author{
This article was published in the following Dove Press journal: \\ Clinical Ophthalmology \\ 8 June 2015 \\ Number of times this article has been viewed
}

\author{
Fariba Ghassemi \\ Alireza Khodabande \\ Eye Research Center, Farabi Eye \\ Hospital, Tehran University of Medical \\ Sciences, Tehran, Tehran Province, \\ Islamic Republic of Iran
}

\begin{abstract}
This manuscript focuses on high-risk factors of metastatic disease in retinoblastoma and evaluation of the current treatments of retinoblastoma. Presence of histopathologic high-risk factors is associated with a higher risk of local recurrence and systemic metastasis. Currently, globe-sparing therapies, including systemic chemotherapy, intra-arterial chemoreduction, intravitreal chemotherapy, focal consolidation, and combination therapies, are being used and investigated actively. Major advances are being made in the diagnosis and management of retinoblastoma that will lead to improved morbidity and mortality rates in patients with retinoblastoma. By saving the globes, fronting with some high-risk factors for metastasis would be inevitable. International multi-institutional prospective studies could resolve current uncertainties regarding the main tumor treatment regimens for each patient and indications for chemoprophylaxis for high-risk-factor-bearing retinoblastoma cases.
\end{abstract}

Keywords: retinoblastoma, intra-arterial chemotherapy, systemic chemotherapy

\section{Introduction}

Retinoblastoma, a curable cancer of childhood, accounts for $2 \%-4 \%$ of all childhood malignancies. ${ }^{1,2}$ Its prevalence is approximately 1:15,000-1:20,000 and can occur unilaterally or bilaterally, with single or multiple foci per eye. ${ }^{3,4}$ Retinoblastoma can occur sporadically $(60 \%)$ or be inherited $(40 \%)$ in an autosomal dominant mode. ${ }^{4}$ Since the past century, prognosis has substantially improved, as only $30 \%$ of affected patients survived in the 1930 s, $80 \%$ in the 1960 s, and $95 \%$ in the 1990 s. $^{5}$ The clinical management of retinoblastoma requires multidisciplinary teamwork and treatment, affecting not only visual outcomes but also ocular retention and morbidity.

Inactivation of both $R B 1$ alleles is the rate-limiting step in retinoblastoma tumorigenesis, but how this tumor acquires the additional changes that constitute a malignant phenotype remains to be determined. ${ }^{6}$ Molecular genetic studies with identification of germ-line mutations have made a tremendous impact on the management of siblings and offspring of affected individuals. ${ }^{7,8}$ They can obviate the need for prolonged clinical screening under anesthesia for many unaffected children and unnecessary need for lifetime follow-up for nonhereditary cases. These workups enable the possibility of preimplantation genetic diagnosis, an option that is likely to be considered by affected individuals. ${ }^{9}$

Invasive retinoblastoma with higher recurrence rate, termed "high-risk" factors, ranges from $0 \%$ to $81 \%$ of all retinoblastoma tumors in the literature. ${ }^{10-15}$ There have been numerous retrospective studies attempting to identify which patients are at highest risk for metastatic disease after enucleation. ${ }^{16-21}$ Considering the high-risk factors, the benefit of adjuvant therapy in preventing relapses after enucleation is addressed in the literature, although there are no prospective, randomized studies.
Eye Research Center, Farabi Eye Hospital, Qazvin Square, Tehran |3366|635|, Tehran Province, Islamic Republic of Iran

Tel +98 2l 5542 I006/+98 2l 55400014

Fax +98 21 554I 6134

Email ghasemi_f@sina.tums.ac.ir 
This review focuses on the main clinical and pathologic risk factors of invasive retinoblastoma and the current treatment options and then will briefly comment on choosing the treatment protocol.

\section{High risks in retinoblastoma Histopathologic and clinical high-risk factors}

Defining high-risk factor either clinically or histopathologically is of outmost importance for the discussion on retinoblastoma patients. There are three major events causing death in patients with retinoblastoma: second malignant neoplasm, pinealoblastoma, and metastasis. ${ }^{11,12}$ Presence of histopathologic high-risk factors is associated with a higher risk of local recurrence and systemic metastasis. Early recognition of the risk factors, followed by prompt treatment, may reduce the incidence of metastatic death.

Metastatic retinoblastoma is reported to develop in less than $10 \%$ of patients in developed countries. ${ }^{13-16}$ High-risk retinoblastoma leads to metastasis in $24 \%$ of patients if not treated with systemic chemotherapy, compared with $4 \%$ of those who receive it. ${ }^{17}$ However, it is a significant contributor to retinoblastoma-related mortality in developing nations..$^{22,23}$ Clinical, genetic, and histopathologic features have been already identified and appreciated as risk factors for metastatic disease. ${ }^{24}$ The main histopathologic high-risk factors have been already defined, including anterior chamber seeding, iris and ciliary body infiltration, tumor invasion beyond the lamina cribrosa (in the neural parenchyma, cerebrospinal fluid, and neural blood vessels), involved optic nerve transection site, massive choroidal infiltration $(>3 \mathrm{~mm})$, scleral infiltration, and extrascleral extension. ${ }^{25-27}$

There are still controversies about the cell type, degree of differentiation, and necrosis in retinoblastoma as risk factors for metastasis. ${ }^{28-30}$ Increasing grade of anaplasia, as defined by increasing cellular pleomorphism, number of mitoses, nuclear size, nuclear hyperchromatism, and necrosis, was associated with decreased overall survival and increased risk of metastasis. ${ }^{31,32}$ Karcioglu et al ${ }^{32}$ concluded that the number of tumor vessels in the enucleated eye may be a useful predictor for metastasis in retinoblastoma.

The International Classification of Retinoblastoma can predict those eyes with high-risk retinoblastoma. Groups A, $\mathrm{B}$, and $\mathrm{C}$ eyes rarely come to enucleation for histopathologic inspection. In an assessment of 519 enucleated eyes, Kaliki et a ${ }^{26}$ found that $17 \%$ of Group D and $24 \%$ of Group E eyes displayed high-risk features for metastatic disease. There was no metastasis in any patient classified with no high-risk retinoblastoma. ${ }^{26}$
Reported clinical predictors of high-risk histopathology in retinoblastoma include older age, longer lag period before diagnosis and treatment, hyphema, pseudohypopyon, staphyloma, and orbital cellulitis. ${ }^{33-39}$ Messmer $^{40}$ quantified and found delays of $\geq 120$ days to be statistically significant for the development of metastatic retinoblastoma. Patients presenting with glaucoma and/or buphthalmia have significantly elevated pathologic risk factors, including those resulting in microscopically residual disease and optic nerve invasion. ${ }^{33,41,42}$

Genetically, non-germ-line tumors had higher tumor stages, more local invasion, more bone marrow involvement and cerebrospinal fluid invasion, higher rates of enucleation, and poorer histologic differentiation. However, germ-line tumors had a greater risk of mortality, phthisis bulbi, and orbital involvement despite earlier diagnosis and lower tumor stage at the time of diagnosis. ${ }^{24}$ Kopelman et $\mathrm{al}^{27}$ in a multivariate analysis focusing on laterality of retinoblastoma found that if patients with concurrent optic nerve and orbital extension were removed from the analysis, patients with bilateral retinoblastoma were more likely to develop metastatic disease $(P=0.0029)$. This could be due to a genetic difference between these tumors or it could simply be due to the fact that bilateral retinoblastoma patients have more tumors (larger tumor volumes). ${ }^{27}$

The standard intravenous chemotherapy protocol using vincristine, etoposide, and carboplatin (VEC) resulted in complete tumor control in all (100\%) high-risk cases with no evident metastasis. ${ }^{25,43}$

\section{Nonocular tumor risk}

The high risk of secondary nonocular tumors in survivors of retinoblastoma has been recognized for some decades. ${ }^{44-51}$ Patients with hereditary retinoblastoma carry a significant risk of secondary nonocular tumors. ${ }^{44}$ External beam radiation therapy administered before the age of 12 months is known to increase this risk. ${ }^{52,53}$

Levene ${ }^{45}$ and Reese et al ${ }^{46}$ reported secondary tumors following treatment in cases of bilateral retinoblastoma. Sagerman et $\mathrm{a}^{47}$ reported cases of osteosarcoma following retinoblastoma and subsequently raised the possibility that there was an increased susceptibility to neoplasia in retinoblastoma cases. Since then, other studies showed a high incidence of nonocular tumor compared with the general population, the risk being largely confined to the heritable group. ${ }^{54,55}$

Current evidence suggests that retinoblastoma survivors, especially hereditary ones and those who received external beam radiation, should be closely monitored for the risk of developing second and third cancers, especially 
in adulthood. ${ }^{50,52,55}$ Other researchers documented the main observed categories of nonocular tumors in the heritable cases as soft tissue sarcomas (mainly leiomyosarcoma), osteosarcoma, carcinomas, brain and central nervous system tumors, melanoma, leukemia, and others. ${ }^{49,51,55}$ More than a single type of tumor can occur in survivors. ${ }^{55}$ Osteosarcoma below the age of 50 years was approximately 200 times as high as the population rate for all bone tumors. ${ }^{52}$ Carcinomas can occur in breast, gastrointestinal system, respiratory tract, skin, or genitourinary system following retinoblastoma tumors. ${ }^{50,52,55}$ Melanoma was reported in the third and fourth decades in heritable cases of retinoblastoma survivals. ${ }^{52,55}$ It seems that patients with retinoblastoma, mainly hereditary cases, are at increased risk for secondary acute myelogenous leukemia after systemic chemotherapy. ${ }^{54-64}$

Based on these studies, it would be prudent to develop a screening protocol for survivors of retinoblastoma, taking into consideration the observed timing suspected of second tumors at various locations in the body.

\section{Classification of retinoblastoma}

A clinical staging system is essential to enable proper definition, treatment plan, outcomes assessment of disease, and international communication. ${ }^{65}$ Several classifications for retinoblastoma were already presented, including the Reese Ellsworth Classification, the Philadelphia Classification of Retinoblastoma, the International Classification of Retinoblastoma, and classification based on the American Joint Commission on Cancer's AJCC Staging Manual Seventh Edition. ${ }^{66-70}$ In 1969, the first classification of intraocular retinoblastoma was introduced by Reese and Ellsworth for prediction of the outcome of external beam radiotherapy. ${ }^{66}$ In 2003, the International Intraocular Retinoblastoma Classification (IIRC) was accepted for prediction of outcomes for eyes treated with chemotherapy. ${ }^{65,67}$ Some difficulties in the definition of higher stages of retinoblastoma tumors (Groups D and E) and changes to the clinical criteria of each stage have made the IIRC inconsistent in some studies. ${ }^{71,72}$ These discrepancies affect the prognostic value of the IIRC, leading to both over- and undertreatment. ${ }^{73}$

The need for including the clinical and pathological findings in predicting the final outcome of patients on management has led to the suggestion of TNM clinical classification by The AJCC and the International Union against Cancer. ${ }^{69,70}$ The TNM staging system for all solid tumors was devised by Pierre Denoix between 1943 and 1952, using the size and extension of the primary tumor (T), its lymphatic involvement $(\mathrm{N})$, and the presence of metastases $(\mathrm{M})$ to classify the progression of cancer. ${ }^{69,70,74}$ Because of the rarity of extraocular extension at the time of diagnosis and even less common enucleation rate, nowadays, this classification system itself is not very often used.

\section{Clinical management of retinoblastoma}

The management of retinoblastoma involves a multidisciplinary approach requiring careful consideration of treatment efficacy and toxicity for saving the life, globe, and possible vision. ${ }^{75-78}$

\section{Enucleation}

Timely enucleation reduces risk of metastatic spread, morbidity, side effects of chemotherapy and focal laser treatment, and repeated examinations under anesthesia. ${ }^{73,76,79,80}$ Enucleation is typically reserved for massive retinoblastoma classified as Group E, some eyes with advanced Group D, and eyes suspected to have extraocular extension (eg, orbital cellulitis, poor view of the inside of the eye, intraocular hemorrhage, neovascular glaucoma, tumor in anterior chamber, suspicious optic nerve involvement, or suspected extraocular disease on imaging). Following enucleation for retinoblastoma, special attention should be paid to the possible tumor spread to determine the possible danger for metastatic disease.

Orbital implants are important for subsequent bone growth and a good cosmetic appearance. ${ }^{73}$ Risk of orbital disease is not a reason to avoid an implant because imaging and treatment of orbital recurrence can be treated without interference from the implant. ${ }^{73}$

Families' rejection of enucleation as curative treatment is not uncommon. With appropriate support, even children who lose both eyes to retinoblastoma can go on to lead full and highly productive lives. ${ }^{73}$

In general, primary enucleation is conducted for advanced stage of retinoblastoma (Group E)-bearing eyes with anterior segment involvement.

\section{Globe-preserving treatments in retinoblastoma}

Globe-saving methods of treatment available to the ocular oncologist include systemic or regional chemotherapy, ${ }^{81,82}$ laser, ${ }^{83}$ and cryotherapy, ${ }^{84}$ while external beam radiation ${ }^{85}$ or plaque radiotherapy are less commonly used. ${ }^{86}$

\section{Chemotherapy for retinoblastoma}

The management of retinoblastoma with chemotherapy is a complex science. Many problems should be considered after 
the diagnosis of the tumor. Choosing the best treatment after diagnosis depends on the intraocular extent of the tumor, laterality of the tumors, and patient's age. The combination of chemotherapeutic agents and the combining of other local adjunctive treatment (thermotherapy, cryotherapy, or plaque radiotherapy) during the chemotherapy and/or after chemotherapy is of particular importance for proper management of disease.

\section{Intravenous chemotherapy}

Presenting of systemic chemotherapy with different protocols was a major advance in retinoblastoma management in recent years. The aim of chemoreduction is to avoid enucleation and external beam radiotherapy and preserve the globe and vision with focal adjunctive treatments. Chemoreduction was introduced as management for retinoblastoma in the mid-1990s following preliminary observations that chemotherapy delivered before external beam radiotherapy increased tumor control with ocular salvage from $30 \%$ to $70 \% .{ }^{87}$ In 1996 , some leading studies stated that systemic chemotherapy was efficient in the short-term control of the tumors in various stages of retinoblastoma. ${ }^{88-91}$ Later analysis showed $90 \%$ tumor control in Reese-Ellsworth Groups I-IV retinoblastoma by six cycles of VEC and focal thermo- or cryotherapy, without need for enucleation or additional external beam radiotherapy. ${ }^{92}$

Systemic chemotherapy generally involves different multidrug regimens delivered intravenously on a monthly basis for 6-9 consecutive months. ${ }^{81,94,95}$ The most popular regimen is 6 months chemotherapy with standard-dose VEC on the basis of patient weight for patients $<3$ years of age..$^{81,93-95}$

According to the international classification of retinoblastoma, in 249 consecutive eyes, globe salvage was achieved in $100 \%$ of Group A eyes, 93\% of Group B, 90\% of Group C, $47 \%$ of Group D, and $25 \%$ of Group E eyes. ${ }^{94}$ Wilson et $\mathrm{al}^{94}$ used vincristine and carboplatin alone (without tumor consolidation) for 36 eyes with retinoblastoma for eight cycles over a period of 6 months. They found complete tumor control in only $8 \%$ of eyes, whereas $92 \%$ had failure with progression of retinal tumor, subretinal seeds, or vitreous seeds. It provided a rationale to use tumor adjunctive local treatments and also the importance of triple chemotherapy regimen to improve the tumor control rate. Eyes with extensive retinoblastoma, classified as Group E, are the most difficult eyes to treat with systemic chemotherapy. Historically, these eyes were generally managed with enucleation. However, when both eyes are of Group E, an attempt to save at least one eye with chemoreduction is made. Eyes of Groups D and E can show improved control with the addition of low-dose radiotherapy, given 2 months after completion of chemoreduction. ${ }^{95,96}$

Systemic toxicity as transient myelosuppression and fever are common in systemic chemoreduction. Rarely, hearing and renal toxicity, as well as leukemia, can be seen. ${ }^{81,97-100}$ Even though these adverse events are treatable and do not result in the cessation of therapy, physicians administering the treatment and counseling the families of affected patients should be aware of the potential complications and should communicate the risks to the families. ${ }^{99,100}$ In 2000, a dramatic decrease in the incidence of pinealoblastoma in children treated with systemic chemotherapy was noted, and this result was confirmed 13 years later. ${ }^{101-103}$ In addition to control of malignancy, systemic chemotherapy offers remarkable visual results with visual acuity at 20/20-20/40 in 37\%-50\% of patients. ${ }^{104,105}$ In general, systemic chemotherapy is administered primarily for patients with bilateral retinoblastoma tumors, familial cases of retinoblastoma, any suspicion of extensive choroidal and optic nerve involvement, and cases younger than 4 months of age.

\section{Intra-arterial chemotherapy}

Recently, local targeted chemotherapy as the direct injection of chemotherapy agents into the ophthalmic artery was popularized. This technique is highly effective in treating higher-stage tumors and saving most eyes otherwise destined for enucleation and, similar to other treatment modalities, can benefit from supplemental focal treatments such as cryotherapy, laser, and brachytherapy. Success with intraarterial chemotherapy (IAC) requires special skill and high experience. Reports have shown good rates of tumor control and minimal side effects. ${ }^{106-108}$ Yamane et al ${ }^{106}$ and Suzuki and Kaneko ${ }^{107}$ first reported the successful use of intra-arterial melphalan using a microballoon, guiding catheter, and flushing hub.

Abramson et al ${ }^{108}$ reported a technique of delivering melphalan directly through a microcatheter into the ostium of the ophthalmic artery without the need for a microballoon. Hence, some groups developed different strategies to improve the results in these high-risk eyes. ${ }^{109-113}$

IAC generally involves a one- to three-drug regimen. The medication is delivered slowly over a period of 30 minutes in a pulsatile manner, with care taken to not occlude the artery and to minimize reflux into the internal carotid artery. ${ }^{108,109}$ The IAC is considered primary or secondary treatment in the management of retinoblastoma cases. ${ }^{110}$

In a 4-year perspective, Gobin et $\mathrm{al}^{114}$ found that IAC was well tolerated and effective for retinoblastoma with globe 
salvage at 2 years in $82 \%$ of eyes if IAC was the primary treatment and $58 \%$ of eyes if it was the secondary treatment. A 5-year experience with IAC by Shields et $\mathrm{al}^{115}$ revealed IAC success in globe salvage in $100 \%$ of Group B, $100 \%$ of Group C, $94 \%$ of Group D, and 36\% of Group E eyes. In that series, complete regression was achieved for solid tumor in $94 \%$ of eyes, for subretinal seeds in $95 \%$ of eyes, and for vitreous seeds in $87 \%$ of eyes. ${ }^{115}$ Thampi et al ${ }^{111}$ noted $86 \%$ response rate in Groups A, B, and C but only $38 \%$ response in Groups $\mathrm{D}$ and $\mathrm{E}$. Schaiquevich et $\mathrm{al}^{112}$ found that IAC was more effective than periocular and intravenous topotecan-containing regimen for treatment of relapsed retinoblastoma.

Other researchers showed synergistic activity of combination melphalan and topotecan IAC and cyclophosphamide in their pharmacokinetic study. ${ }^{116,117}$ The combination of melphalan and topotecan for IAC of retinoblastoma was effective and well tolerated without increased hematologic toxicity with respect to melphalan administered as a single drug. ${ }^{117,118}$ Topotecan showed a preferential passage to the vitreous humor, where it stayed for at least 4 hours more than its calculated $\mathrm{IC}_{50}(50 \%$ inhibitory concentration $) .{ }^{119}$

Melphalan showed a less-favorable penetration into the vitreous humor but was present at higher levels in the retinal pigment epithelium, which could explain its excellent efficacy for the treatment of eyes with retinal detachment caused by the tumor. ${ }^{118}$

The IAC is a sophisticated technique. Vaso-occlusive disease has been described following IAC as a potentially sightthreatening complication. ${ }^{116,120-122}$ Histopathologic examination of a nonhuman primate model for IAC revealed significant toxic effects in the ocular and orbital vasculature. ${ }^{121}$ An overall assessment of complications with 5-year experience included vitreous hemorrhage (2\%), branch retinal artery obstruction ( $1 \%$ ), ophthalmic artery spasm with reperfusion (2\%), ophthalmic artery obstruction $(2 \%)$, partial choroidal ischemia $(2 \%)$, and optic neuropathy $(<1 \%) .{ }^{122}$ Other studies showed eyelid edema, blepharoptosis, cilia loss, and orbital congestion with temporary dysmotility, retinal detachments, cataract, and retinal pigment epithelium damage (47\%). ${ }^{122,123}$

Theoretically, this technique may pose a risk for brain vascular events and other operation territory vessels. ${ }^{124-126}$ Sarici et al ${ }^{125}$ noted the "blue toe" syndrome as a complication. Episodes of adverse cardiorespiratory reactions, such as hypoxia, hypotension, and bradycardia, have been documented in $24 \%$ of procedures in a recent report from the UK. ${ }^{126}$ Reactions occurred only during the second or subsequent procedures and these can be life threatening. ${ }^{126}$ Tsimpida et $\mathrm{al}^{127}$ studied visual outcome following IAC and noted that $5(43 \%)$ out of 12 treated eyes had severe visual loss due to choroidal ischemia or retinal detachment. The authors caution regarding visual complications from this therapy due to possible factors of catheterization or high doses of melphalan.

This treatment technique could be performed as the primary option in the following cases: unilateral cases of retinoblastoma, nonheritable cases of unilateral retinoblastomas, and cases older than 4 months of age.

\section{Periocular chemotherapy}

Periocular chemotherapy is usually indicated for bilateral advanced Groups D or E in which a higher local dose of chemotherapy is required and in some patients with recurrent localized tumor. Periocular chemotherapy achieves rapid levels and six to ten times higher level than that achieved by the intravenous route within the vitreous humor in 30 minutes and can last for hours. ${ }^{128,129}$ The method of injection can vary from plain liquid injection; injection within a depot such as gels, Lincoff balloon, long-acting fibrin sealant, or nanoparticles; solid polymers; or injection stimulated by iontophoresis. ${ }^{128-130}$ Most clinicians use either carboplatin or topotecan. Periocular injection of carboplatin has been used for retinoblastoma control for $>2$ decades, generally as an adjunct to systemic chemotherapy but occasionally to treat tumor recurrence. ${ }^{130}$ Periocular topotecan is injected in a fibrin sealant or as an episcleral implant. ${ }^{131,132}$

Local side effects include inflammation, ptosis, scarring, and loss of sight. ${ }^{132,133}$ Yousef et al ${ }^{134}$ found that periocular topotecan was effective and led to fewer complications of fibrosis compared to carboplatin with a mean follow-up period of 37 months.

Periocular chemotherapy could be used in advanced tumors (D or E) or recurrences with the need for greater local dosage of the chemotherapeutic agents.

\section{Intravitreal chemotherapy}

Intravitreal chemotherapy (IViC) for retinoblastoma was tried for the first time in the 1960s using thio- $N, N^{\prime}, N^{\prime}$ triethylenethiophosphoramide (thio-TEPA) and later with methotrexate. ${ }^{135,136}$ Inomata and Kaneko ${ }^{137}$ found melphalan to be the most effective against retinoblastoma on the basis of in vitro testing. Recently, Suzuki et al reported five years results of intravitreal injection of 8-30 mg melphalan combined with ocular hyperthermia for vitreous tumor seeding in 264 eyes of 250 patients. Sixty-eight percent of the treated eyes achieved complete vitreous seed remission. ${ }^{138}$ 
Munier et $\mathrm{al}^{139}$ studied IViC in 23 patients with heavily treated retinoblastoma, with recurrent vitreous seeds. They injected 20-30 mg intravitreal melphalan on a weekly basis and found $83 \%$ success rate of tumor seeds control at 15 months. Ghassemi and Shields ${ }^{140}$ evaluated 12 eyes treated with intravitreal melphalan for recurrent vitreous seeding and defined proper dosing. They identified that low-dose melphalan (8-10 mg) showed 42\% control and minimal side effects, whereas high doses, such as a $50-\mathrm{mg}$ dose, were toxic with possible hypotonia and phthisis bulbi. ${ }^{140}$ They concluded that melphalan has promising results with 30-50 mg, not more. In another study, they showed that of 25 IViC-treated cases, eight eyes needed enucleation because of phthisis, parent request, or new tumor development. There was no case of needle-site scleral involvement by retinoblastoma cells. ${ }^{141,142}$

Subsequently, Shields et al ${ }^{143}$ reviewed an additional 55 injections for recurrent vitreous seeding in 16 retinoblastoma cases, which led to globe salvage in all cases $(100 \%)$. Ghassemi et $\mathrm{al}^{143}$ studied the addition of intravitreal topotecan with melphalan in humans and noted that this led to complete vitreous seed control with a single injection (33\%) or two or three injections $(67 \%)$, without the need for the standard six injections.

Reported complications with IViC were mostly minor retinal pigment epithelial mottling at the site of injection and extra-axial cataract. However, more significant side effects such as preretinal hemorrhage, vitreous hemorrhage, subretinal hemorrhage, retinal detachment, iris atrophy, hypotonia, and phthisis could be seen in some patients. ${ }^{139-141}$ There was no reported case of extraocular tumor extension so far.

The main point is the time of considering IViC. This includes patients with unresponsive vitreous seeds to standard treatments and recurrent seeds after complete treatment. It is clear that the present drugs and the doses used are not effective for the treatment of residual tumors. Additionally, multiple injections of IViC agent as either a single agent or double agents did not preclude new tumor development. ${ }^{139,143}$ The future path should be to develop new and more specific drugs for combating new tumors or even the main tumor by intravitreal injections.

In the Farabi Eye Hospital, we inject the IViC drugs on a biweekly schedule until the vitreous seeds disappear or crystallize. If any viable seeds are visible in any part of the vitreous cavity, despite some crystallization, the injections are continued. We conduct IViC for patients with the following indications: recurrent or residual vitreous seedings after systemic or IAC and monocular patients with any type of vitreous seedings after completion or during the systemic chemotherapy or IAC.

Theoretically, tumor seeding can occur following IViC. Smith et $\mathrm{al}^{145}$ in a review of all published cases or series on IViC from 1946 to 2013, found that a total of 1,304 intravitreal injections were given in 315 eyes of 304 patients and that only one patient developed metastatic disease. They concluded that proper technique leads to no increased risk of tumor spread. ${ }^{145}$

In the next few years, by increasing the survival of retinoblastoma patients and preserving greater number of sick globes, systemic metastasis and local recurrences will be plausible, due to the possible persistence of viable cells after complete treatment. An international, multi-institutional prospective study, with access to larger series of patients with retinoblastoma, could resolve current uncertainties.

Regarding the recurrence prophylaxis, development of appropriate chemotherapy agents and doses, the ideal treatment regimen, and new types of adjunctive treatments is expected. Ongoing gene therapy research in cancer may in future reach clinical practice, but numerous technical hurdles remain to be overcome. ${ }^{146}$ In the present era, development of both new guidelines for defining the high risks and appropriate guidelines for chemoprophylaxis in patients afflicted with advanced forms of this disease is necessary.

\section{Acknowledgment}

The authors would like to thank Professor Carol Shields and Professor Jerry Shields for their expert advice in this project.

\section{Author contributions}

Both authors contributed equally to hypothesis creation, intervention application, data collection, and article writing; and agree to be accountable for all aspects of the work.

\section{Disclosure}

The authors report no conflicts of interest in this work.

\section{References}

1. Shields JA, Shields CL. Management and prognosis of retinoblastoma. In: Shields JA, Shields CL, editors. Intraocular Tumors. A Text and Atlas. Philadelphia: WB Saunders; 1992:377-392.

2. Shields JA, Shields CL. Retinoblastoma. In: Shields JA, Shields CL, editors. Atlas of Intraocular Tumors. Philadelphia: Lippincott Williams Wilkins; 2008:293-365.

3. MacCarthy A, Draper GJ, Steliarova-Foucher E, Kingston JE. Retinoblastoma incidence and survival in European children (1978-1997). Report from the automated childhood cancer information system project. Eur J Cancer. 2006;42(13):2092-2102. 
4. Cavenee WK, Dryja TP, Phillips RA, et al. Expression of recessive alleles by chromosomal mechanisms in retinoblastoma. Nature. 1983; 305(5937):779-784.

5. Shields CL, Meadows AT, Leahey AM, Shields JA. Continuing challenges in the management of retinoblastoma with chemotherapy. Retina. 2004;24(6):849-862.

6. Temming P, Corson TW, Lohmann DR. Retinoblastoma tumorigenesis: genetic and epigenetic changes walk hand in hand. Future Oncol. 2012;8(5):525-528.

7. Lohmann DR, Gallie BL. Retinoblastoma: revisiting the model prototype of inherited cancer. Am J Med Genet C Semin Med Genet. 2004; 129:23-28.

8. Richter S, Vandezande K, Chen N, et al. Sensitive and efficient detection of RB1 gene mutations enhances care for families with retinoblastoma. Am J Hum Genet. 2003;72:253-269.

9. Simpson JL, Carson SA, Cisneros P. Preimplantation genetic diagnosis (PGD) for heritable neoplasia. J Natl Cancer Inst Monogr. 2005;34:87-90.

10. Bosaleh A, Sampor C, Solernou V, et al. Outcome of children with retinoblastoma and isolated choroidal invasion. Arch Ophthalmol. 2012;130(6):724-729.

11. Chantada GL, Casco F, Fandiño AC, et al. Outcome of patients with retinoblastoma and postlaminar optic nerve invasion. Ophthalmology. 2007;114(11):2083-2089.

12. Chantada GL, de Davila MT, Fandino A, et al. Retinoblastoma with low risk for extraocular relapse. Ophthalmic Genet. 1999;20(3):133-140.

13. Chantada GL, Dunkel IJ, de Dávila MT, Abramson DH. Retinoblastoma patients with high risk ocular pathological features: who needs adjuvant therapy? Br J Ophthalmol. 2004;88(8):1069-1073.

14. Hungerford J. Factors influencing metastasis in retinoblastoma. $\mathrm{Br} J$ Ophthalmol. 1993;77(9):541.

15. Singh AD, Shields CL, Shields JA. Prognostic factors in retinoblastoma. J Pediatr Ophthalmol Strabismus. 2000;37(3):134-141.

16. Kivela T. Trilateral retinoblastoma: a meta-analysis of hereditary retinoblastoma associated with primary ectopic intracranial retinoblastoma. J Clin Oncol. 1999;17(6):1829-1837.

17. Shields CL, Shields JA. Recent developments in the management of retinoblastoma. J Pediatr Ophthalmol Strabismus. 1999;36(1):8-18.

18. Ries LAG, Smith MA, Gurney JG, et al. Cancer Incidence and Survival Among Children and Adolescents: United States SEER Program 1975-1995. Bethesda, MD: National Cancer Institute, SEER Program; 1999:73-78. [NIH publication: 99-4649].

19. de Sutter E, Havers W, Hopping W, Alberti W. The prognosis of retinoblastoma in terms of survival, II: a computer assisted study. Ophthalmic Paediatr Genet. 1987;8(2):85-88.

20. Abramson DH, Niksarli K, Ellsworth RM, Servodidio CA. Changing trends in the management of retinoblastoma: 1951-1965 vs 1966-1980. J Pediatr Ophthalmol Strabismus. 1994;31(1):32-37.

21. Honavar SG, Singh AD, Shields CL, et al. Postenucleation adjuvant therapy in high-risk retinoblastoma. Arch Ophthalmol. 2002; 120(7):923-931.

22. Gündüz K, Köse K, Kurt RA, et al. Retinoblastoma in Turkey: results from a tertiary care center in Ankara. J Pediatr Ophthalmol Strabismus. 2013;50(5):296-303.

23. Ali MJ, Honavar SG, Reddy VA. Distant metastatic retinoblastoma without central nervous system involvement. Indian J Ophthalmol. 2013; 61(7):357-359.

24. Finger PT, Harbour JW, Karcioglu ZA. Risk factors for metastasis in retinoblastoma. Surv Ophthalmol. 2002;47(1):1-16.

25. Eagle RC Jr. High-risk features and tumor differentiation in retinoblastoma: a retrospective histopathologic study. Arch Pathol Lab Med. 2009;133(8):1203-1209.

26. Kaliki S, Shields CL, Rojanaporn D. High-risk retinoblastoma based on international classification of retinoblastoma: analysis of 519 enucleated eyes. Opthalmology. 2013;120(3):997-1003.

27. Kopelman JE, McLean IW, Rosenberg SH. Multivariate analysis of risk factors for metastasis in retinoblastoma treated by enucleation. Ophthalmology. 1987;94(4):371-377.
28. McLean IW, Rosenberg SH, Messmer EP, et al. Prognostic factors in cases of retinoblastoma: analysis of 974 patients from Germany and the United States treated by enucleation. In: Bornfeld N, Gragoudas ES, Hopping W, editors. Tumors of the Eye. Amsterdam, Netherlands: Kugler; 1991:69-72.

29. Suryawanshi P, Ramadwar M, Dikshit R, et al. A study of pathologic risk factors in postchemoreduced, enucleated specimens of advanced retinoblastomas in a developing country. Arch Pathol Lab Med. 2011;135(8):1017-1023.

30. Chantada GL, Dunkel IJ, Antoneli CB, et al. Risk factors for extraocular relapse following enucleation after failure of chemoreduction in retinoblastoma. Pediatr Blood Cancer. 2007;49(3):256-260.

31. Chong EM, Coffee RE, Chintagumpala M, Hurwitz RL, Hurwitz MY, Chévez-Barrios P. Extensively necrotic retinoblastoma is associated with high-risk prognostic factors. Arch Pathol Lab Med. 2006;130(11): 1669-1672.

32. Karcioglu ZA, Parson Bamgboye E. Retinoblastoma angiogenesis and prognosis. Exp Eye Res. 1996;63:S69.

33. Shields CL, Shields JA, Baez K, Cater JR, De Potter P. Optic nerve invasion of retinoblastoma. Metastatic potential and clinical risk factors. Cancer. 1994;73(3):692-698.

34. Kashyap S, Meel R, Pushker N, et al. Clinical predictors of high risk histopathology in retinoblastoma. Pediatr Blood Cancer. 2012;58(3): 356-361.

35. DerKinderen DJ, Koten JW, Van Romunde LK, et al. Early diagnosis of bilateral retinoblastoma reduces death and blindness. Int J Cancer. 1989;44(1):35-39.

36. Haik BG, Siedlecki A, Ellsworth RM, Sturgis-Buckhout L. Documented delays in the diagnosis of retinoblastoma. Ann Ophthalmol. 1985; 17(11):731-732.

37. Shields JA, Shields CL, Suvarnamani C, Schroeder RP, DePotter P. Retinoblastoma manifesting as orbital cellulitis. Am J Ophthalmol. 1991;112(4):442-449.

38. Stafford WR, Yanoff M, Parnell BL. Retinoblastomas initially misdiagnosed as primary ocular inflammations. Arch Ophthalmol. 1969;82(6):771-773.

39. Robertson DM, Campbell RJ. Analysis of misdiagnosed retinoblastoma in a series of 726 enucleated eyes. Mod Probl Ophthalmol. 1977;18: $156-159$.

40. Messmer EP, Heinrich T, Höpping W, de Sutter E, Havers W, Sauerwein W. Risk factors for metastases in patients with retinoblastoma. Ophthalmology. 1991;98(2):136-141.

41. Temming P, Viehmann A, Biewald E, Lohmann DR. Sporadic unilateral retinoblastoma or first sign of bilateral disease? Br J Ophthalmol. 2013;97(4):475-480.

42. Chantada GL, Gonzalez A, Fandino A, et al. Some clinical findings at presentation can predict high-risk pathology features in unilateral retinoblastoma. J Pediatr Hematol Oncol. 2009;31(5): 325-329.

43. Kaliki S, Shields CL, Shah SU, Eagle RC Jr, Shields JA, Leahey A. Postenucleation adjuvant chemotherapy with vincristine, etoposide, and carboplatin for the treatment of high-risk retinoblastoma. Arch Ophthalmol. 2011;129(11):1422-1427.

44. Abramson DH, Ellsworth RM, Kitchin FD, Tung G. Second nonocular tumors in retinoblastoma survivors: are they radiationinduced? Ophthalmology. 1984;91(11):1351-1355.

45. Levene M. Congenital retinoblastoma and sarcoma botryoides of the vagina: report of a case. Cancer. 1960;13:532-537.

46. Reese AB, Merriam GR, Martin HE. Treatment of bilateral retinoblastoma by irradiation and surgery. Report on 15-year results. Am J Ophthalmol. 1949;32(2):175-190.

47. Sagerman RH, Cassady JR, Tretter P, Ellsworth RM. Radiation induced neoplasia following external beam therapy for children with retinoblastoma. Am J Roentgenol. 1969;105(3):529-535.

48. Fletcher O, Easton D, Anderson K, Gilham C, Jay M, Peto J. Lifetime risks of common cancers among retinoblastoma survivors. J Natl Cancer Inst. 2004;96(5):357-363. 
49. Kleinerman RA, Tucker MA, Tarone RE, et al. Risk of new cancers after radiotherapy in long-term survivors of retinoblastoma: an extended follow-up. J Clin Oncol. 2005;23(10):2272-2279.

50. Moll AC, Imhof SM, Bouter LM, et al. Second primary tumors in patients with hereditary retinoblastoma: a register-based follow-up study, 1945-1994. Int J Cancer. 1996;67(4):515-519.

51. Acquaviva A, Ciccolallo L, Rondelli R, et al. Mortality from second tumour among long-term survivors of retinoblastoma: a retrospective analysis of the Italian retinoblastoma registry. Oncogene. 2006;25(38):5350-5357.

52. Abramson DH, Frank CM. Second nonocular tumors in survivors of bilateral retinoblastoma: a possible age effect on radiation-related risk. Ophthalmology. 1998;105(4):573-579.

53. Moll AC, Imhof SM, Schouten-Van Meeteren AY, Kuik DJ, Hofman P, Boers M. Second primary tumors in hereditary retinoblastoma: a register-based study, 1945-1997. Is there an age effect on radiationrelated risk? Ophthalmology. 2001;108(6):1109-1114.

54. Office for National Statistics. Cancer Statistics: Registrations. Registrations of Cancer Diagnosed in 2005, England. London: HMSO; 2008. [MB1 No. 36].

55. MacCarthy A, Bayne AM, Draper GJ, et al. Non-ocular tumours following retinoblastoma in Great Britain 1951 to 2004. Br J Ophthalmol. 2009;93(9):1159-1162.

56. Gombos DS, Hungerford J, Abramson DH, et al. Secondary acute myelogenous leukemia in patients with retinoblastoma: is chemotherapy a factor? Ophthalmology. 2007;114(7):1378-1383.

57. Smith MA, Rubinstein L, Ungerleider RS. Therapy-related acute myeloid leukemia following treatment with epipodophyllotoxins: estimating the risks. Med Pediatr Oncol. 1994;23(2):86-98.

58. Smith MA, McCaffrey RP, Karp JE. The secondary leukemias: challenges and research directions. J Natl Cancer Inst. 1996;88(7):407-418.

59. Pui CH, Ribeiro RC, Hancock ML, et al. Acute myeloid leukemia in children treated with epipodophyllotoxins for acute lymphoblastic leukemia. N Engl J Med. 1991;325(24):1682-1687.

60. Smith MA, Rubinstein L, Anderson JR, et al. Secondary leukemia or myelodysplastic syndrome after treatment with epipodophyllotoxins. J Clin Oncol. 1999;17(2):569-577.

61. Sauerbrey A, Stammler G, Zintl F, Volm M. Expression of the retinoblastoma tumor suppressor gene (RBrb-1) in acute leukemia. Leuk Lymphoma. 1998;28(3-4):275-283.

62. La Starza R, Wlodarska I, Aventin A, et al. Molecular delineation of 13q deletion boundaries in 20 patients with myeloid malignancies. Blood. 1998;91(1):231-237.

63. Ahuja HG, Jat PS, Foti A, Bar-Eli M, Cline MJ. Abnormalities of the retinoblastoma gene in the pathogenesis of acute leukemia. Blood. 1991;78(12):3259-3268.

64. Jamal R, Gale RE, Shaun N, Thomas B, Wheatley K, Linch DC. The retinoblastoma gene (rb1) in acute myeloid leukaemia: analysis of gene rearrangements, protein expression and comparison of diseases outcome. Br J Haematol. 1996;94(2):342-351.

65. Linn Murphree A. Intraocular retinoblastoma: the case for a new group classifi cation. Ophthalmol Clin North Am. 2005;18(1):41-53.

66. Ellsworth RM. The practical management of retinoblastoma. Trans Am Ophthalmol Soc. 1969;67:462-534.

67. Shields CL, Mashayekhi A, Demirci H, Meadows AT, Shields JA. Practical approach to management of retinoblastoma. Arch Ophthalmol. 2004;122(5):729-735

68. Shields CL, Shields JA. Basic understanding of current classification and management of retinoblastoma. Curr Opin Ophthalmol. 2006;17(3): 228-234.

69. Denoix PF. Enquete permanent dans les centres anticancereaux [Permanent investigation in the anti- cancer centers]. Bull Inst Nat Hyg. 1946;1:70-75. French.

70. Edge SB, Byrd DR, Compton CC, et al. editors. AJCC Cancer Staging Manual. 7th ed. New York: Springer; 2010:561-568.

71. Mallipatna CA, Dimaras H, Hon E, Gallie BL. Published international classification of retinoblastoma (ICRB) definitions contain inconsistencies: an analysis of impact. Evidence Based Ophthalmol. 2009;10:183-185.
72. Novetsky DE, Abramson DH, Kim JW, Dunkel IJ. Published international classification of retinoblastoma (ICRB) definitions contain inconsistencies - an analysis of impact. Ophthalmic Genet. 2009;30(1):40-44.

73. Dimaras H, Kimani K, Dimba EA, et al. Retinoblastoma. Lancet. 2012;379(9824):1436-1446.

74. Finger P, Harbour J, Murphree A, et al. Chapter 52: retinoblastoma. In: Edge SB, Byrd DR, Compton CC, Fritz AG, Greene FL, Trotti A, editors. AJCC Cancer Staging Manual. 7th ed. Berlin: Springer Science and Business Media; 2010:561-568.

75. Shields CL, Kaliki S, Rojanaporn D, Al-Dahmash S, Bianciotto CG, Shields JA. Intravenous and intra-arterial chemotherapy for retinoblastoma: what have we learned. Curr Opin Ophthalmol. 2012;23(3): 202-209.

76. Shields CL, Shields JA. Retinoblastoma management: advances in enucleation, intravenous chemoreduction, and intra-arterial chemotherapy. Curr Opin Ophthalmol. 2010;21(3):203-212.

77. Chawla B, Jain A, Azad R. Conservative treatment modalities in retinoblastoma. Indian J Ophthalmol. 2013;61(9):479-485.

78. Shields CL, Fulco EM, Arias JD, et al. Retinoblastoma frontiers with intravenous, intra-arterial, periocular, and intravitreal chemotherapy. Eye (Lond). 2013;27(2):253-264.

79. Zhao J, Dimaras H, Massey C, et al. Pre-enucleation chemotherapy for eyes severely affected by retinoblastoma masks risk of tumor extension and increases death from metastasis. J Clin Oncol. 2011;29(7): 845-851.

80. Schiedler V, Dubovy SR, Murray TG. Snare technique for enucleation of eyes with advanced retinoblastoma. Arch Ophthalmol. 2007;125(5): 680-683.

81. Chan HS, Gallie BL, Munier FL, Beck Popovic M. Chemotherapy for retinoblastoma. Ophthalmol Clin North Am. 2005;18(1):55-63.

82. Tsui JY, Dalgard C, Van Quill KR, et al. Subconjunctival topotecan in fibrin sealant in the treatment of transgenic murine retinoblastoma. Invest Ophthalmol Vis Sci. 2008;49(2):490-496.

83. Augsburger JJ, Faulkner CB. Indirect ophthalmoscope argon laser treatment of retinoblastoma. Ophthalmic Surg. 1992;23(9): 591-593.

84. Shields JA, Shields CL. Treatment of retinoblastoma with cryotherapy. Trans Pa Acad Ophthalmol Otolaryngol. 1990;42:977-980.

85. Chan MPY, Hungerford JL, Kingston JE, Plowman PN. Salvage external beam radiotherapy after failed primary chemotherapy for bilateral retinoblastoma: rate of eye and vision preservation. Br J Ophthalmol. 2009;93(7):891-894.

86. Shields CL, Shields JA, Cater J, Othmane I, Singh AD, Micaily B. Plaque radiotherapy for retinoblastoma: long-term tumor control and treatment complications in 208 tumors. Ophthalmology. 2001;108(11): 2116-2121.

87. Kingston JE, Hungerford JL, Madreperla SA, Plowman PN. Results of combined chemotherapy and radiotherapy for advanced intraocular retinoblastoma. Arch Ophthalmol. 1996;114(11): 1339-1343.

88. Schefler AC, Cicciarelli N, Feuer W, Toledano S, Murray TG. Macular retinoblastoma: evaluation of tumor control, local complications, and visual outcomes for eyes treated with chemotherapy and repetitive foveal laser ablation. Ophthalmology. 2007;114(1):162-169.

89. Gallie BL, Budning A, DeBoer G, et al. Chemotherapy with focal therapy can cure intraocular retinoblastoma without radiotherapy. Arch Ophthalmol. 1996;114(11):1321-1328.

90. Murphree AL, Villablanca JG, Deegan WF 3rd, et al. Chemotherapy plus local treatment in the management of intraocular retinoblastoma. Arch Ophthalmol. 1996;114(11):1348-1356.

91. Shields CL, De Potter P, Himelstein BP, Shields JA, Meadows AT, Maris JM. Chemoreduction in the initial management of intraocular retinoblastoma. Arch Ophthalmol. 1996;114(11):1330-1338.

92. Shields CL, Honavar SG, Meadows AT, et al. Chemoreduction plus focal therapy for retinoblastoma: factors predictive of need for treatment with external beam radiotherapy or enucleation. Am J Ophthalmol. 2002;133(5):657-664. 
93. Leahey AM. Systemic chemotherapy: a pediatric oncology perspective. In: Ramasubramanian A, Shields CL, editors. Retinoblastoma. New Delhi, India: Jaypee Brothers Medical Publishers; 2012:81-85.

94. Wilson MW, Rodriguez-Galindo C, Haik BG, Moshfeghi DM, Merchant TE, Pratt CB. Multiagent chemotherapy as neoadjuvant treatment for multifocal intraocular retinoblastoma. Ophthalmology. 2001;108(11):2106-2115.

95. Shields CL, Mashayekhi A, Au AK, et al. The international classification of retinoblastoma predicts chemoreduction success. Ophthalmology. 2006;113(12):2276-2280.

96. Berry JL, Jubran R, Kim JW, et al. Long-term outcomes of Group D eyes in bilateral retinoblastoma patients treated with chemoreduction and low-dose IMRT salvage. Pediatr Blood Cancer. 2013;60(4): 688-693.

97. Lambert MP, Shields CL, Meadows AT. A retrospective review of hearing in children with retinoblastoma treated with carboplatin-based chemotherapy. Pediatr Blood Cancer. 2008;50(2):223-226.

98. Leahey A. A cautionary tale: dosing chemotherapy in infants with retinoblastoma. J Clin Oncol. 2012;30(10):1023-1024.

99. Benz MS, Scott IU, Murray TG, Kramer D, Toledano S. Complications of systemic chemotherapy as treatment of retinoblastoma. Arch Ophthalmol. 2000;118(4):577-578.

100. Turaka K, Shields CL, Leahey A, Meadows AT. Second malignant neoplasms following chemoreduction with carboplatin, etoposide, and vincristine in 245 patients with intraocular retinoblastoma. Pediatr Blood Cancer. 2012;59(1):121-125.

101. Shields CL, Shields JA, Meadows AT. Chemoreduction for retinoblastoma may prevent trilateral retinoblastoma [letter]. J Clin Oncol. 2000;18(1):236-237.

102. Shields CL, Meadows AT, Shields JA, Carvalho C, Smith AF. Chemoreduction for retinoblastoma may prevent intracranial neuroblastic malignancy (trilateral retinoblastoma). Arch Ophthalmol. 2001;119(9):1269-1272.

103. Ramasubramanian A, Kytasty C, Meadows AT, Shields JA, Leahey A, Shields CL. Incidence of pineal gland cyst and pineoblastoma in children with retinoblastoma during the chemoreduction era. Am J Ophthalmol. 2013;156(4):825-829.

104. Demirci H, Shields CL, Meadows AT, Shields JA. Long-term visual outcome following chemoreduction for retinoblastoma. Arch Ophthalmol. 2005;123(11):1525-1530.

105. Kivela T. Alive with good vision: the ultimate goal in managing retinoblastoma. Clin Exper Ophthalmol. 2012;40(7):655-656.

106. Yamane T, Kaneko A, Mohri M. The technique of ophthalmic arterial infusion therapy for patients with intraocular retinoblastoma. Int J Clin Oncol. 2004;9(2):69-73.

107. Suzuki S, Kaneko A. Management of intraocular retinoblastoma and ocular prognosis. Int J Clin Oncol. 2004;9(1):1-6.

108. Abramson DH, Dunkel IJ, Brodie SE, Kim JW, Gobin YP. A phase I/II study of direct intraarterial (ophthalmic artery) chemotherapy with melphalan for intraocular retinoblastoma: initial results. Ophthalmology. 2008;115(8):1398-1404.

109. Marr BP, Brodie SE, Dunkel IJ, Gobin YP, Abramson DH. Three-drug intra-arterial chemotherapy using simultaneous carboplatin, topotecan and melphalan for intraocular retinoblastoma: preliminary results. Br J Ophthalmol. 2012;96(10):1300-1303.

110. Ghassemi F, Ghanaati H, Karkhaneh R, Boujabadi L, Tabatabaie SZ, Rajabi MT. Outcome of retinoblastoma following limited sessions of intra-arterial chemotherapy in Iran. Iran J Radiol. 2014;11(3): e16958.

111. Thampi S, Hetts SW, Cooke DL, et al. Superselective intra-arterial melphalan therapy for newly diagnosed and refractory retinoblastoma: results from a single institution. Clin Ophthalmol. 2013;7:981-989.

112. Schaiquevich $\mathrm{P}$, Ceciliano A, Millan N, et al. Intra-arterial chemotherapy is more effective than sequential periocular and intravenous chemotherapy as salvage treatment for relapsed retinoblastoma. Pediatr Blood Cancer. 2013;60(5):766-770.
113. Francis JH, Gobin YP, Dunkel IJ, et al. Carboplatin $+/-$ topotecan ophthalmic artery chemosurgery for intraocular retinoblastoma. PLoS One. 2013;8(8):e72441.

114. Gobin YP, Dunkel IJ, Marr BP, Brodie SE, Abramson DH. Intraarterial chemotherapy for the management of retinoblastoma: four-year experience. Arch Ophthalmol. 2011;129(6):732-737.

115. Shields CL, Manjandavida FP, Lally SE, et al. Intra-arterial chemotherapy for retinoblastoma in 70 eyes: outcomes based on the international classification of retinoblastoma. Ophthalmology. 2014;121(7):1453-1460.

116. Saylors RL 3rd, Stewart CF, Zamboni WC, et al. Phase I study of topotecan in combination with cyclophosphamide in pediatric patients with malignant solid tumors: a Pediatric Oncology Group Study. J Clin Oncol. 1998;16(3):945-952.

117. Taich P, Ceciliano A, Buitrago E, et al. Clinical pharmacokinetics of intraarterial melphalan and topotecan combination in patients with retinoblastoma. Ophthalmology. 2014;121(4):889-897.

118. Schaiquevich P, Buitrago E, Ceciliano A, et al. Pharmacokinetic analysis of topotecan after superselective ophthalmic artery infusion and periocular administration in a porcine model. Retina. 2012;32(2): 387-395.

119. Palioura S, Gobin YP, Brodie SE, Marr BP, Dunkel IJ, Abramson DH. Ophthalmic artery chemosurgery for the management of retinoblastoma in eyes with extensive $(>50 \%)$ retinal detachment. Pediatr Blood Cancer. 2012;59(5):859-864.

120. Shields CL, Bianciotto CG, Jabbour P, et al. Intra-arterial chemotherapy for retinoblastoma: report No. 2, treatment complications. Arch Ophthalmol. 2011;129(11):1407-1415.

121. Munier FL, Beck-Popovic MB, Balmer A, Gaillard MC, Bovey E, Binaghi S. Occurrence of sectoral choroidal occlusive vasculopathy and retinal arteriolar embolization after superselective ophthalmic artery chemotherapy for advanced intraocular retinoblastoma. Retina. 2011; 31(3):566-573.

122. Shields CL, Lally SE, Leahey AM, Jabbour PM, Caywood EH, Schwendeman R, Shields JA. Targeted retinoblastoma management: when to use intravenous, intra-arterial, periocular, and intravitreal chemotherapy. Curr Opin Ophthalmol. 2014;25(5): 374-385.

123. Suesskind D, Schrader M, Foerster MH, Ernemann U, Aisenbrey S. Cataract formation: a possible complication of intra-arterial chemotherapy for retinoblastoma. Eur J Ophthalmol. 2014;24(3): 449-453.

124. Muen WJ, Kingston JE, Robertson F, Brew S, Sagoo MS, Reddy MA. Efficacy and complications of super-selective intra-ophthalmic artery melphalan for the treatment of refractory retinoblastoma. Ophthalmology. 2012;119(3):611-616.

125. Sarici A, Kizilkilic O, Celkan T, Gode S. Blue toe syndrome as a complication of intra-arterial chemotherapy for retinoblastoma. JAMA Ophthalmol. 2013;131(6):801-802.

126. Phillips TJ, McGuirk SP, Chahal HK, et al. Autonomic cardiorespiratory reflex reactions and super selective ophthalmic arterial chemotherapy for retinoblastoma. Paediatr Anaesth. 2013;23(10): 940-945.

127. Tsimpida M, Thompson DA, Liasis A, et al. Visual outcomes following intraophthalmic artery melphalan for patients with refractory retinoblastoma and age appropriate vision. Br J Ophthalmol. 2013;97(11): 1464-1470.

128. Mendelsohn ME, Abramson DH, Madden T, Tong W, Tran HT, Dunkel IJ. Intraocular concentrations of chemotherapy following systemic or local administration. Arch Ophthalmol. 1998;116(9): 1209-1212.

129. Hayden BC, Jockovich ME, Murray TG, et al. Pharmacokinetics of systemic versus focal carboplatin chemotherapy in the rabbit eye: possible implication in the treatment of retinoblastoma. Invest Ophthalmol Vis Sci. 2004;45(10):3644-3649.

130. Abramson DH, Frank CM, Dunkel IJ. A phase I/II study of subconjunctival carboplatin for intraocular retinoblastoma. Ophthalmology. 1999;106(10):1947-1950. 
131. Mallipatna AC, Dimaras H, Chan HS. Periocular topotecan for intraocular retinoblastoma. Arch Ophthalmol. 2011;129(6): 738-745.

132. Carcaboso AM, Chiappetta DA, Opezzo JA. Episcleral implants for topotecan delivery to the posterior segment of the eye. Invest Ophthalmol Vis Sci. 2010;51(4):2126-2134.

133. Mulvihill A, Budning A, Jay V, et al. Ocular motility changes after subtenon carboplatin chemotherapy for retinoblastoma. Arch Ophthalmol. 2003;121(8):1120-1124.

134. Yousef YA, Halliday W, Chan HS, Héon E, Gallie BL, Dimaras H. No ocular motility complications after subtenon topotecan with fibrin sealant for retinoblastoma. Can J Ophthalmol. 2013;48(6): 524-528.

135. Ericson LA, Kalberg B, Rosengren BH. Trials of intravitreal injections of chemotherapeutic agents in rabbits. Acta Ophthalmol. 1964;42(4):721-726.

136. Kivela T, Eskelin S, Paloheimo M. Intravitreal methotrexate for retinoblastoma. Ophthalmology. 2011;118(8):1689, 1689.e1-.e6.

137. Inomata M, Kaneko A. Chemosensitivity profiles of primary and cultured retinoblastoma cells in a human tumor clonogenic assay. Jpn J Cancer Res. 1987;78(8):858-868.

138. Suzuki S, Aihara Y, Fujiwara M, Sano S, Kaneko A. Intravitreal injection of melphalan for intraocular retinoblastoma. Jpn J Ophthalmol. Epub 2015 Mar 13.

139. Munier FL, Gaillard MC, Balmer A, et al. Intravitreal chemotherapy for vitreous disease in retinoblastoma revisited: from prohibition to conditional indications. Br J Ophthalmol. 2012;96(8):1078-1083.
140. Ghassemi F, Shields CL. Intravitreal melphalan for refractory or recurrent vitreous seeding from retinoblastoma. Arch Ophthalmol. 2012;130(10):1268-1271.

141. Ghassemi F, Amoli FA. Pathological findings in enucleated eyes after intravitreal melphalan injection. Int Ophthalmol. 2014; 34(3):533-540.

142. Smith SJ, Smith BD. Evaluating the risk of extraocular tumour spread following intravitreal injection therapy for retinoblastoma: a systematic review. Br J Ophthalmol. 2013;97(10):1231-1236.

143. Shields CL, Manjandavida FP, Arepalli S, Kaliki S, Lally SE, Shields JA. Intravitreal melphalan for persistent or recurrent retinoblastoma vitreous seeds: preliminary results. JAMA Ophthalmol. 2014;132(3):319-325.

144. Ghassemi F, Shields CL, Ghadimi H, Khodabandeh A, Roohipoor R. Combined intravitreal melphalan and topotecan for refractory or recurrent vitreous seeding from retinoblastoma. JAMA Ophthalmol. 2014;132(8):936-941.

145. Smith SJ, Smith BD, Mohney BG. Ocular side effects following intravitreal injection therapy for retinoblastoma: a systematic review. Br J Ophthalmol. 2014;98(3):292-297.

146. Philiponnet A, Grange JD, Baggetto LG. Application of gene therapy to oncologic ophthalmology. J Fr Ophtalmol. 2014;37(2):155-165.

\section{Clinical Ophthalmology}

\section{Publish your work in this journal}

Clinical Ophthalmology is an international, peer-reviewed journal covering all subspecialties within ophthalmology. Key topics include: Optometry; Visual science; Pharmacology and drug therapy in eye diseases; Basic Sciences; Primary and Secondary eye care; Patient Safety and Quality of Care Improvements. This journal is indexed on Submit your manuscript here: http://www.dovepress.com/clinical-ophthalmology-journal

\section{Dovepress}

PubMed Central and CAS, and is the official journal of The Society of Clinical Ophthalmology (SCO). The manuscript management system is completely online and includes a very quick and fair peer-review system, which is all easy to use. Visit http://www.dovepress.com/ testimonials.php to read real quotes from published authors. 